\title{
Effect of CFRP Confinement on AAR-Induced Expansion of Concrete Columns
}

\author{
THAMER KUBAT ${ }^{*, * *}$, RIADH AL-MAHAIDI ${ }^{*}$ and AHMAD SHAYAN ${ }^{* * *}$ \\ *Swinburne University of Technology, Melbourne- Australia (corresponding author) \\ ** Duhok Polytechnic Institute, Duhok, Kurdistan Region-Iraq \\ *** ARRB Group Ltd, Melbourne-Australia
}

\section{ABSTRACT}

The effect of the alkali-aggregate reaction (AAR) in concrete, which has an adverse effect on its durability. In order to extend concrete'service life-span it is necessary to find a novel material to reduce or limit AAR-induced expansion and improve the strength capacity of the affected concrete. Carbon fibre reinforced polymers (CFRPs) are one of several materials used to rehabilitate affected concrete members. Twenty circular concrete columns $200 \mathrm{~mm}$ in diameter and $500 \mathrm{~mm}$ in height were cast from reactive (AAR) concrete. During six months of storage at $38^{\circ} \mathrm{C}$ and $98 \%$ relative humidity, several ages of $15,30,45,60,90$ and 120 days after casting to represent different levels of expansion during AAR development were selected to confine the affected columns using CFRP composites. Strain behaviour in concrete and steel were monitored, before and after confinement, for different wrapping times. The results indicate the efficiency of using CFRP to reduce the rate of expansion in both steel and concrete. The results show also show that the efficiency of reducing AAR-induced expansion depends on the time of wrapping and the number of CFRP layers applied to the affected columns.

KEY WORDS: Alkali aggregate reaction (AAR), Carbon fibre reinforced polymer (CFRP), Strain, Expansion, Confinement

\section{INTRODUCTION}

I $n$ the past few decades, the alkaliaggregate reaction (AAR) has been considered as a phenommenon that still has an adverse effect on the durability of concrete. "Cancer of concrete" is an expression used by several researchers to describe the behavior of the alkali-aggregate reaction (AAR) in concrete. AAR is a chemical reaction between alkaline compounds in the cement paste with certain constituents in the aggregate in the presence of high relative humidity from the external environment, causing the formation of gels. These gels have the capability to expand by absorbing moisture and to develop tensile stresscaused cracks if the latter stresses exceed the tensile strength of concrete, subsequently affecting structural integrity. Fiber reinforced polymer (FRP) is one of the best approches, effective and novel, which can be used to restrain AAR expansion and forces and enhance the strength and ductility capacities of deteriorated concrete structures.
The use of FRP in the rehabilitation of AARaffected concrete structures has been the concern of a number of researchers who have investigated the effectiveness of the new composite material. The confinement of standard cylinders or prisms affected by AAR with carbon fibre reinforced polymer (CFRP) has been studied by several researchers (Qian et al., 2001; Curtil et al., 2003; Wigum, 2003; Mohamed et al., 2005; Mohamed et al.,2006; Pelletier and Labossière, 2007), and others have used this material on flexural and compression concrete members (Fujii et al., 1996; Lacasse et al., 2003; Abdullah et al., 2010; Shayan et al., 2012). The following sub-sections focus on the effectiveness of CFRP use for confining affected concrete columns to restrain AAR-induced expansion and enhance the strength and strain capacities.

The effect of unidirectional CFRP as a composite material to confine 12 concrete cylinders $160 \mathrm{~mm}$ in diameter and $320 \mathrm{~mm}$ in length was investigated by Mohamed et al. (2005). Six samples were reactive and six nonreactive. Three cylinders for each concrete type 
were confined. After confinement, the cylinders were kept at a temperature of $38{ }^{\circ} \mathrm{C}$ and relative humidity (RH) of $100 \%$. After 8 months of monitoring expansion in the transverse and longitudinal directions, the results showed that confinement by CFRP reduced transverse and longitudinal expansion by $75 \%$ and $21 \%$, respectively. The effectiveness of CFRP wrapping for the confinement of AAR-affected concrete piles was investigated by Shayan et al. (2009). Based on their results, the researchers concluded that:

- The wrapping of damaged piles with CFRP only slowed the expansion rate but deleterious expansion continued.

- CFRP wrapping did not completely contain the lateral expansion of columns with square crosssections, but this could not be fully attributed to the non-circular (square) cross-section of the piles, although CFRP is more effective in confining columns with circular cross-sections.

- Future research is required to include types of CFRP with different mechanical properties (modulus and tensile strength) and the use of sufficient numbers of CFRP layers which can be applied at different stages of AAR development to find their effect in restraining AAR expansion.

High modulus CFRP for confining columns of highly expansive concrete was investigated by Abdullah et al. (2010). The CFRP was applied during the active stage of AAR at the age of one month. The results showed that this type of CFRP of low tensile capacity $(0.4 \%)$ was not adequate for use with highly expansive concrete, but it could be used with low expansive concrete.

The main objective of the present research is to investigate the efficiency of the application of CFRP as a confinement material to reduce the effect of AAR-induced expansion on concrete through the selection of different levels of expansion during AAR development in reducing AAR residual expansion. A secondary objective is to study the probability of debonding between steel reinforcement and concrete at a certain level of AAR expansion by monitoring the deformation in the reinforcement and the expansion in the concrete.

\section{MATERIAL}

\subsection{Concrete mixture}

One concrete mix of proportions 0.42: 1: 1.7: 2.54 (water-cement ratio: cement: fine aggregate: coarse aggregate) was used throughout the research. General purpose cement was used for the mix. The percentage of alkalinity of the cement was $0.5 \%$ expressed as sodium oxide equivalent $\left(\mathrm{Na}_{2} \mathrm{O}_{\text {equ }}\right)$ according to the manufacturer's information. Crushed aggregate of $19 \mathrm{~mm}$ maximum size was used. Sodium hydroxide was added to water in the mix to increase the level of alkalinity in reactive concretes ( $\mathrm{Rc}$ ) to $1.25 \%$ expressed as $\mathrm{Na}_{2} \mathrm{O}_{\text {equ }}$ according to the ASTM C1293 requirements. Fused silica of $0-1 \mathrm{~mm}$ fraction grading from Sila Australia was used in the mix of Rc. Fused silica is made from high purity silica and is over $99 \%$ amorphous and it was used at a dosage rate of $7.5 \%$ by mass of total aggregate, replacing the fine aggregate component. Fused silica was used as a reactive component within the aggregate, due to its uniformity compared to natural aggregates.

\subsection{Steel reinforcement and CFRP}

Two diameters of deformed bars were used in the reinforced columns: $10 \mathrm{~mm}$ for longitudinal reinforcement (rebar) and $6.0 \mathrm{~mm}$ for transverse reinforcement (ties). One type of high tensile CFRP (CF 230 (modulus of elasticity, GPa)/4900 (tensile strength, MPa) 400 (weight, gm per $\left.\mathrm{m}^{2}\right) / 50$ (width, $\mathrm{mm}$ )) fabric was used throughout the research to wrap the specimens. MBrace Saturant epoxy was used as a bonding material to wrap the columns with CFRP.

\subsection{Strain gauges}

To measure the axial and lateral expansion in the concrete, two embedded strain gauges model PML-60-2LT were used. This type of strain gauge is provided with a strain transducer to enable long-term use. Thin wires were used to join both strain gauges at right angles and fix them at the centre of the concrete core. Strain gauges of type FLA-5-11-3LT with 5mm gauge length were used to measure the deformations of the longitudinal reinforcement bars and lateral reinforcement (ties) during storage.

\subsection{Details of columns}

The experimental work included casting twenty circular reinforced columns $204 \mathrm{~mm}$ in diameter and $500 \mathrm{~mm}$ in height. These columns were reinforced longitudinally with $5 \varnothing 10 \mathrm{~mm}$ deformed bar and 4 ties of $\varnothing 6 \mathrm{~mm}$ deformed bar. 
The reinforcement ratio used for the main reinforcement was $1.17 \%$ and $0.35 \%$ for the secondary reinforcement (ties).

\subsection{Storage conditions}

All columns were stored under the conditions set out in ASTM 1293 from demoulding up to 180 days after casting. These columns were stored in a special saturation cabinet $6000 \times 720$ $\mathrm{x} 880 \mathrm{~mm}$ (length $\mathrm{x}$ width $\mathrm{x}$ depth) at a temperature of $38^{\circ} \mathrm{C}$ and relative humidity of 98\% through the storage time.

\subsection{Confinement}

During six months of storage at the specified temperature and under relative humidity conditions, confinement with CFRP was applied for different periods during AAR development, i.e., 15, 30, 45, 60, 90 and 120 days after casting, representing different levels of AAR expansion using one and two layers of CFRP. Table 1 shows the details of columns.

Table (1): Details of columns.

\begin{tabular}{lccccccc}
\hline Wrapping time (days) & $\mathbf{1 5}$ & $\mathbf{3 0}$ & $\mathbf{4 5}$ & $\mathbf{6 0}$ & $\mathbf{9 0}$ & $\mathbf{1 2 0}$ & Unconfined \\
\hline Number of layers (L) & 1 & 1,2 & 1 & 1,2 & 1 & 1,2 & ---- \\
\hline Number of columns & 2 & 4 & 2 & 4 & 2 & 4 & 2 \\
\hline
\end{tabular}

\subsection{Strain measurement}

A data-logger was used to take readings of strain gauges during the storage period of the columns. Readings of expansion in concrete, in both directions, radial and axial, and the deformation in steel reinforcement (rebar \& ties) were taken regularly up to the age of 180 days after casting. The expansion measurements were taken before and after confinement. Figure 1 shows the stored columns in the cabinet during the recording of strains by the data-logger.

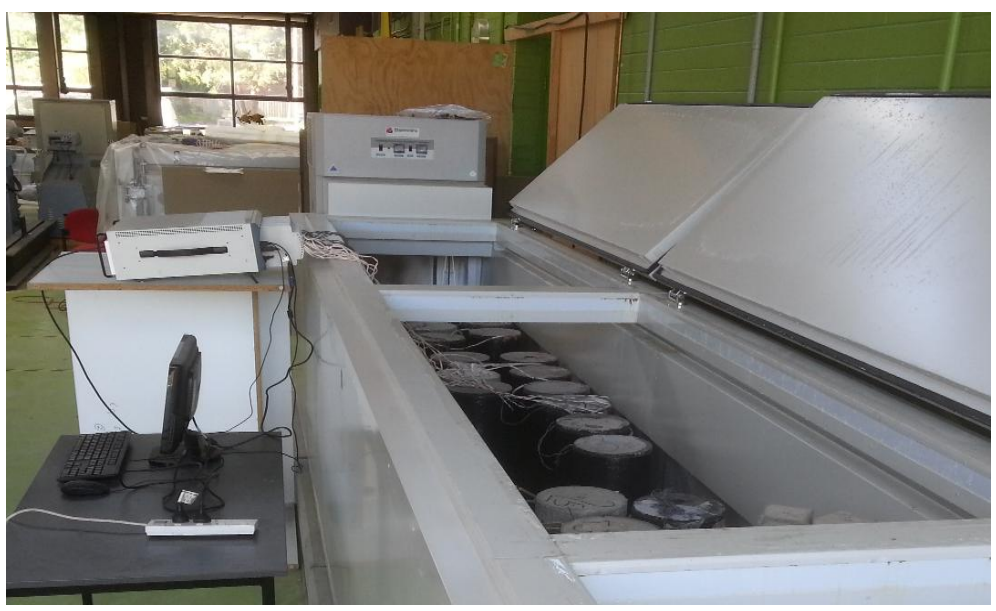

Fig. (1): Mointoring strain in concrete and steel during storage of columns.

\section{RESULTS AND DISCUSSION}

The main purpose of the study was to investigate the effect of wrapping time on strain development in concrete and steel, through the CFRP wrapping of columns at several times after casting, i.e., at different stages during the active stage of AAR development. The affected columns were confined by one layer or two layers of CFRP, at 15, 30, 45, 60, 90 and 120 days after casting. The expansions were recorded before and after confinement.

\subsection{Effect of Confinement on Concrete Expansion}

The use of CFRP in the confinement of AAR-affected concrete columns significantly 
reduced the expansion in concrete compared to unconfined columns. However, the expansion still continued, i.e., CFRP wrapping did not arrest the AAR-induced expansion. The same observation has been made by Shayan et al. (2009; 2012). The following sub-sections focus on the expansions in concrete, radial and axial, for the affected columns, before and after confinement, during the active stage of AAR.

\subsubsection{Radial direction}

The values recorded for radial expansion, before and after confinement, for different wrapping times of the affected columns were plotted against time up to six months after casting, as shown in Figure 2. The figure also includes unconfined columns. The figure shows that the curves of expansion for confined or unconfined concrete columns have the same trend, but the rate is different. As the figure indicates, wrapping with CFRP reduced the rate of radial expansion of the affected columns, compared with that of the unconfined columns. Due to the residual expansion, wrapping at early ages of AAR development reduced the rate of expansion compared with wrapping at later ages. The increase in wrapping stiffness (two layers of CFRP) reduced the expansion rate compared with less wrapping stiffness (one layer of CFRP) at the same time of wrapping. The 180-day expansion values are the summation of expansion before and after confinement. The results show a reduction in the expansion value at the age of 180 days in columns with different CFRP wrapping times when compared to the unconfined columns at the same age, even if the wrapping was applied at later ages. The CFRP confinement of columns at early ages shows better performance in reducing expansion at the age of 180 days when compared with the unconfined columns at the same age. The results also show the better performance of wrapping with two layers than one layer (30 and 60 days wrapping times) due to the increase in confinement pressure from CFRP layers on the expanding concrete.

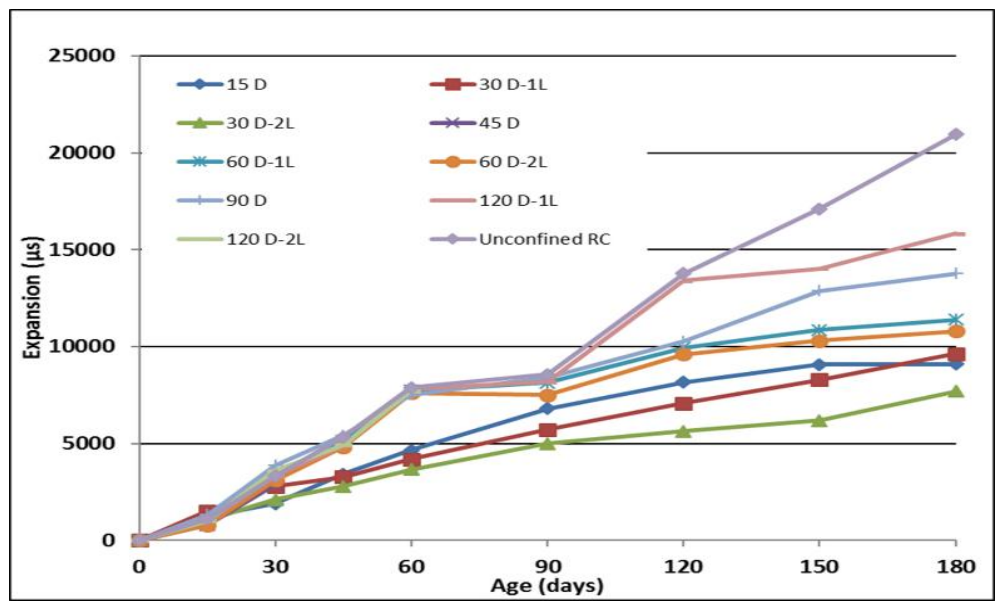

Fig. ( 2): Radial expansion in concrete of confined columns at different times and unconfined columns up to the age of 180 days after casting.

\subsubsection{Axial direction}

The use of uni-directional CFRP meant that expansion in the direction of fibre orientation (radial) was reduced due to restraint in that direction, whereas the other direction (axial) was still greatly affected by AAR expansion. The axial expansion values of confined columns at different wrapping times as well as unconfined columns are plotted in Figure 3 up to the age of 180 days. As the figure shows, the expansion values in the axial direction were affected by confinement but to a lesser degree than radial expansion, due to the type of CFRP used. The rate of expansion was reduced in the axial direction as a result of the effect of wrapping times compared to unconfined columns. The use of two layers of CFRP (more stiffness) increased the expansion in the axial direction more than the use of one layer of CFRP (less stiffness) due to the increased stiffness in the radial direction. 


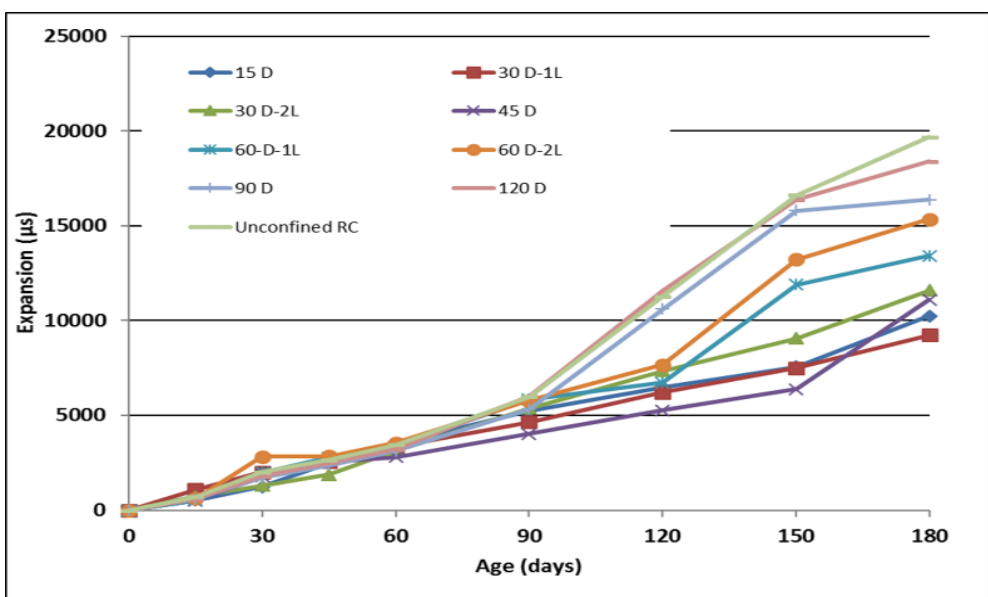

Fi.e( 3): Axial expansion in concrete of confined columns at different times and unconfined columns up to the age of 180 days after casting.

\subsection{Effect of confinement on steel reinforcement}

The expansion of the concrete caused the steel reinforcement to deform. The CFRP confinement of affected columns partially restrained concrete and steel from expansion and deformation, respectively. The following subsections focus on deformations in steel reinforcement (rebar \& ties) for the affected columns, before and after confinement, during the active stage of AAR.

\subsubsection{Rebar deformation}

Deformation of the main reinforcement (rebar) is affected by the expansion of concrete in the same direction. The deformation values for the rebar of affected confined columns are plotted in Figure 4 with the corresponding values for unconfined columns. As shown in the figure, there are two obvious stages in the rate of rebar deformation during AAR development. In the first stage (0-30 days), the main reinforcement showed high rates of deformation ranging from 18.7-32 $\mu$ s/day, whereas the second stage showed significant decreases in the rate to 2.3-5.5 $\mu$ s/day in the period from 30-180 days. At the age of 30 days, the expansion in concrete reached the value of $2000 \mu \mathrm{s}$ in the direction of the rebar, which was sufficient to spread the cracks beyond the steel reinforcement. After that, the presence of micro-cracking may have had an effect on the bond between steel reinforcement and concrete, which reduced the effect of AAR on the rebar. The 180-day deformation values varied between $1000-1900 \mu$ s for different wrapping times of confined columns. The highest value is close to the strain yield of steel.

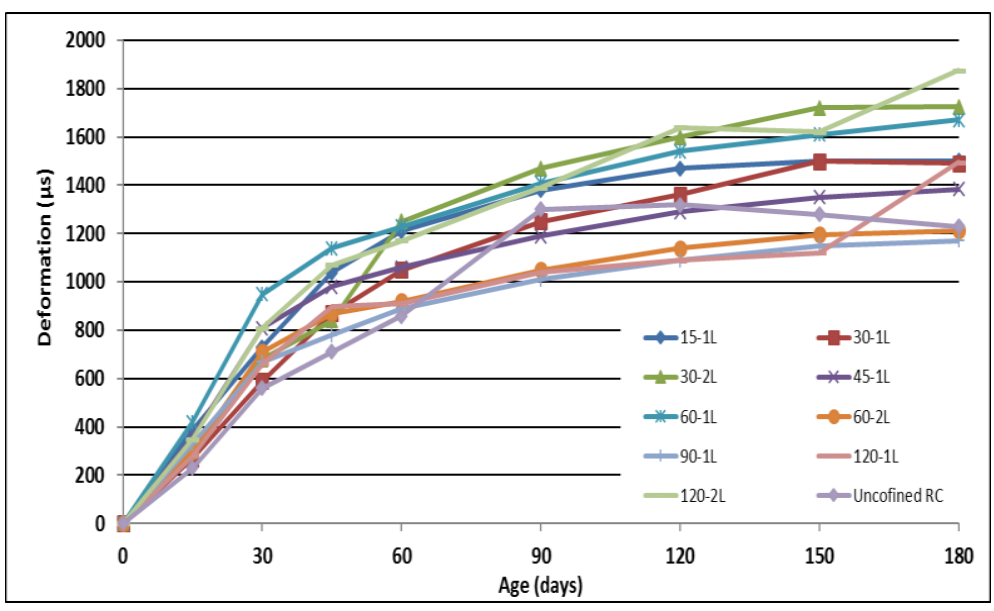

Fig. (4): Deformation in rebar versus time of confined columns at different times and unconfined columns 
The estimation of AAR pressure in concrete $p$ at different CFRP wrapping times can be calculated using Equation 1:

$p($ concrete $)=\frac{A_{S}}{A_{c}} \frac{\varepsilon_{S}}{1-2 v} E_{S}$

where, $A_{c}$ is the sectional area of concrete core and $\mathrm{A}_{\mathrm{s}}, \varepsilon_{\mathrm{s}}, v$ and $E_{S}$ are the area of longitudinal steel, strain, Poisson's ratio and modulus of elasticity of steel, respectively.

The calculated AAR pressures, before and after wrapping, and the 180 days for different wrapping times are presented in Table 2, including the 180-day steel stress generated by AAR. Steel stress values at the age of 180 days were still far from the measured yield strength of

$f_{b c}=0.6\left(0.5+\frac{c}{d}\right) f_{t}$

where, $\mathrm{c}$ and $\mathrm{d}$ are concrete cover and rebar diameter, respectively.

The calculated value of bonding strength at the age of 180 days is $2.55 \mathrm{MPa}$, which is less than the AAR pressure for some cases of the steel used (520 MPa). Concerning the AAR pressure values, the maximum value was reached for confined columns that were wrapped at the age of 120 days (2L). The estimation of bond strength $\left(f_{b c}\right)$ can be calculated using Equation 2, which depends on the measured splitting tensile strength $\left(f_{t}\right)$ of reactive concrete at the age of 180 days (1.7 $\mathrm{MPa})$ : confined columns. The lower value of bonding strength may be an indication of debonding between the steel reinforcement and the concrete.

Table (2): AAR pressure and stress in steel reinforcement (rebar) for confined columns wrapped at different times and unconfined columns.

\begin{tabular}{|c|c|c|c|c|c|c|c|c|c|c|c|}
\hline & & \multicolumn{10}{|c|}{ Wrapping time (days) } \\
\hline & & 15 & \multicolumn{2}{|c|}{30} & 45 & \multicolumn{2}{|c|}{60} & 90 & \multicolumn{2}{|c|}{120} & Unconfined \\
\hline & & \multicolumn{10}{|c|}{ No. of CFRP layers } \\
\hline & & $1 \mathrm{~L}$ & $1 \mathrm{~L}$ & $2 \mathrm{~L}$ & $1 \mathrm{~L}$ & $1 \mathrm{~L}$ & $2 \mathrm{~L}$ & $1 \mathrm{~L}$ & $1 \mathrm{~L}$ & $2 \mathrm{~L}$ & ---- \\
\hline \multicolumn{2}{|c|}{$\mathrm{A}($ rebar $) / \mathrm{A}($ concrete) $(\%)$} & \multicolumn{10}{|c|}{1.17} \\
\hline \multicolumn{2}{|c|}{$\mathrm{E}(\mathrm{GPa})$} & \multicolumn{10}{|c|}{210} \\
\hline \multicolumn{2}{|c|}{$\mathrm{v}$ (poisson ratio) } & \multicolumn{10}{|c|}{0.3} \\
\hline \multirow{3}{*}{$\begin{array}{l}\text { Strain in } \\
\text { rebar } \\
(\mu \mathrm{s})\end{array}$} & $\begin{array}{c}\text { Before } \\
\text { confinement }\end{array}$ & 390 & 590 & 680 & 980 & 1230 & 920 & 1010 & 1090 & 1640 & ---- \\
\hline & $\begin{array}{c}\text { After } \\
\text { confinement }\end{array}$ & 1112 & 900 & 1045 & 404 & 440 & 292 & 160 & 405 & 235 & ----- \\
\hline & $\begin{array}{l}\text { Total at } \\
180 \text { days }\end{array}$ & 1502 & 1490 & 1725 & 1384 & 1670 & 1212 & 1170 & 1495 & 1875 & 1229 \\
\hline \multicolumn{2}{|c|}{$\begin{array}{c}\text { Ultimate stress in } \\
\text { steel (MPa) }\end{array}$} & 315 & 313 & 362 & 291 & 351 & 255 & 246 & 314 & 394 & 258 \\
\hline \multirow{3}{*}{$\begin{array}{l}\text { Pressure } \\
\text { in } \\
\text { concrete } \\
(\mathrm{MPa})\end{array}$} & $\begin{array}{c}\text { Before } \\
\text { confinement }\end{array}$ & 0.6 & 0.91 & 1.04 & 1.5 & 1.89 & 1.41 & 1.55 & 1.67 & 2.52 & ----- \\
\hline & $\begin{array}{c}\text { After } \\
\text { confinement }\end{array}$ & 1.71 & 1.38 & 1.6 & 0.62 & 0.68 & 0.45 & 0.25 & 0.62 & 0.36 & ----- \\
\hline & $\begin{array}{l}\text { Total at } \\
180 \text { days }\end{array}$ & 2.31 & 2.29 & 2.65 & 2.13 & 2.56 & 1.86 & 1.8 & 2.3 & 2.88 & 1.89 \\
\hline
\end{tabular}




\subsubsection{Tie Deformation}

The effect of confinement in reducing the deformation of ties for confined columns compared to unconfined columns is very clear, as shown in Figure 5. The ties normally provide an internal confinement pressure on the core of the column against the expansion of concrete, whereas the external confinement represented by CFRP provides an external confinement pressure on the whole concrete column. The same observation of a high rate of deformation was noticed for ties as well as rebar at the first 30 days after casting. Then the rate of deformation decreased up to the age of 180 days. The confinement by CFRP had a great effect on tie deformations at the age of 180 days. The 180day tie deformation values showed a reduction in the final deformation values in ties for columns which were wrapped at earlier ages. The figure also shows that the increased stiffness of wrapping material reduced the deformation of ties when compared to the lower confinement stiffness at the same time, i.e., the use of two layers of CFRP showed better performance in reducing the deformation in ties than one layer of CFRP. The values of the amplitude deformations of all confined columns wrapped at different times are smaller than the values for the unconfined columns.

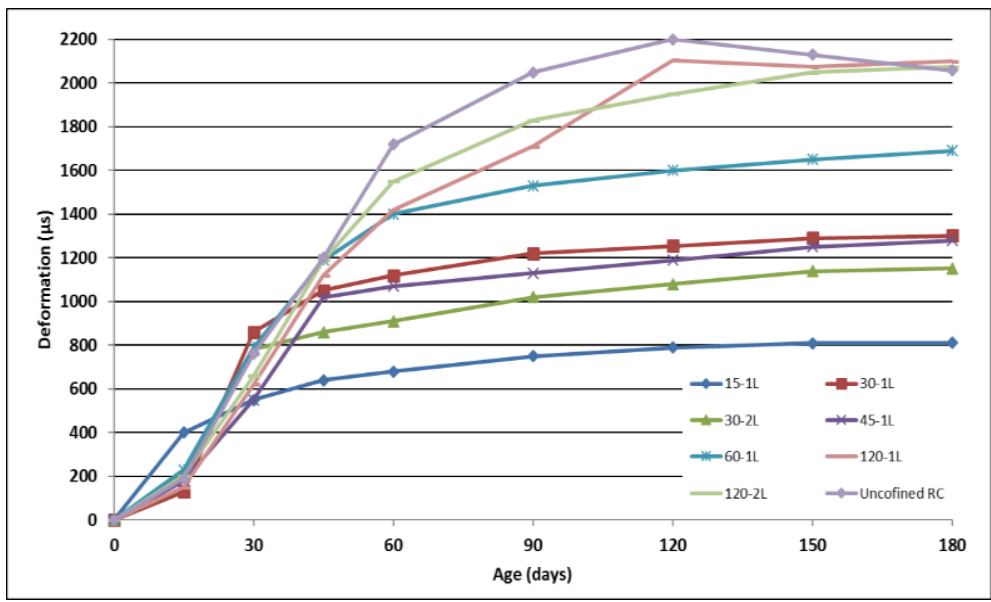

Fig. (5): Deformation in ties versus time of confined columns at different times and unconfined columns.

\section{CONCLUSIONS}

To reduce the expansion induced by AAR, CFRP was used to confine the affected columns. Of 48 columns cast, 36 columns, plain and reinforced, were fabricated from AAR concrete. During the AAR process, CFRP wrapping was used to confine the affected columns at different times after casting, which represented different levels of AAR expansion. One layer or two layers of CFRP were used. The radial and axial expansion values in concrete as well as the deformations in steel reinforcement (rebar \& ties) were recorded and analysed at selected times. Measurement of the expansion in concrete and deformation in steel reinforcement and CFRP enabled the following conclusions to be drawn:

- At high levels of expansion ( $>6000 \mu \mathrm{s}$ ), debonding between steel reinforcement and concrete may occur, which reduces the effect of AAR on reinforcement bars.
- The lower confinement pressure from the ties causes the deformation in the radial direction (ties) to be higher than that in the axial direction (rebar).

- CFRP wrapping is effective in limiting AAR expansion, and has the advantage of being a waterproof layer.

- The rate of radial and axial expansion can be reduced by CFRP confinement, compared with unconfined columns. However, the expansion still continues, i.e., AAR expansion is not stopped by CFRP wrapping.

- The CFRP confinement of columns at early ages shows better performance in reducing expansion than at later ages.

- The use of two layers of CFRP at the ages 30 and 60 days is more effective in restraining AAR expansion than one layer of CFRP, due to the increase in stiffness, which leads to increased confinement pressure on the expanding concrete. 
- The efficiency of reducing AAR expansion depends upon the time of CFRP wrapping and on the number of CFRP layers applied to the column.

- The efficiency of CFRP wrapping is larger when natural aggregates of lower expansion capacity are used compared to fused silica.

\section{ACKNOWLEGEMENTS}

The first author would like to acknowledge the full scholarship support of the Ministry of Higher Education and Scientific Research of Iraq and thanks Duhok Polytechnic Institute for giving him the opportunity to complete the study. Thanks are due to all the staff of the Smart Structures Laboratory at Swinburne University of Technology.

\section{REFERENCES}

- Qian, C., Chen, C. and Gao, J. (2001). Restrained alkali-aggregate expansion of concrete due to external wrapping and its mechanism. Proceedings of the International Conference on High Performance Materials in Bridges (pp. 397-405), Kona, Hawaii, USA.

- Curtil, L., Ferrier, E., Ronel-Idrissi, S. and Hamelin, P. (2003). Composite materials contribution in strengthening concrete structures affected by alkali-aggregate reaction. International Journal of Materials and Product Technology, 19, 68-82.

- Mohamed, I., Curtil, L., Ronel-Idrissi, S. and Hamelin, P. (2005). Influence of composite materials confinement on alkali aggregate expansion. Materials and Structures/Materiaux et Constructions, 38, 387-394.

- Mohamed, I., Ronel, S. and Curtil, L. (2006). Influence of composite materials confinement on alkali-aggregate mechanical behaviour. Materials and Structures/Materiaux et Constructions, 39, 479-490.

- Pelletier, H. and Labossire, P. (2007). Effect of a FRP confinement on the behaviour of concrete cylinders damaged by alkali-aggregate reactions. Annaual Conference of the Canadian Society for Civil Engineering (pp.21-30), Yellowknife, Northwest Territories, Canada.

- Fuji, M., Kobayashi, K., Kojima, T., Adachi, Y. and Kurihara, S. (1996). An experimental study on strengthening ASR-damaged reinforced concrete members with carbon fiber sheet. Proceedings of the 10th International Conference on Alkali-Aggregate Reaction in Concrete (ICAAR) (pp.1041-1048), Melbourne, Victoria, Australia.

- Abdullah, S., Al-Mahaidi, R. and Shayan, A. (2010). CFRP confinement of RC columns damaged by alkali aggregate reaction. In: Proceedings of the 5th Civil Engineering Conference in the Asian Region and the Australasian Structural Engineering Conference (pp.773-778), Sydney, N.S.W, Australia.

- Shayan, A., Xu, A. and Salamy, R. (2012). Confinement of AAR in cylindrical reinforcement columns by CFRP wrapping. Proceedings of the 14th International Conference on Alakli Aggregate Reaction in Concrete (ICAAR) (pp.11), Austin, Texas, USA, May 20-24.

- Shayan, A., Xu, A. and Salamy, R. (2009). Effectiveness of CFRP wrapping in confining the expansion of AAR-affected concrete. In: Austroads 7th Bridge Conference, Auckland, New Zealand, May 24-26. 